\title{
Google Trends Analyses and Case Report: A Persistently Dilated Pupil in Psychedelics' User
}

\author{
Ahmed Al-Imam ${ }^{1,2}$ \\ ${ }^{1}$ Department of Postgraduate Medicine, School of Life and Medical Sciences, University of Hertfordshire, United \\ Kingdom \\ ${ }^{2}$ Department of Anatomy and Cellular Biology, College of Medicine, University of Baghdad, Iraq \\ Correspondence: Dr Ahmed Al-Imam, House 18/5, Al-Akhtal Street, District 318, Al-Adhamyia, 10053, Baghdad, \\ Iraq. E-mail: tesla1452@gmail.com; a.m.al-imam@herts.ac.uk
}

Received: July 25, 2017 Accepted: August 17, 2017 Online Published: September 18, 2017

doi:10.5539/gjhs.v9n11p168 URL: https://doi.org/10.5539/gjhs.v9n11p168

\begin{abstract}
An eighteen years old female patient of the Caucasian ethnicity from New Zealand, she presented with a persistently dilated pupil causing her discomfort and occasional burning sensation when outdoor due to an oversensitivity to sunlight. However, her pupillary reaction to light (pupillary light reflex) was intact. The patient is a known user of psychedelic substances (entheogens) including LSD, NBOMe, psilocybin, and DMT. The condition affects both eyes to the same extent. A thorough medical, neurological, and radiological examination, including an EEG and an MRI of the head and neck region, were completely normal. All these tests failed to detect any pathophysiological or anatomical abnormalities. The patient is a known case of chronic endogenous depression in association with attention deficit hyperactivity disorder, for which she is medicating with citalopram and Ritalin respectively. There was neither a family history nor a similar congenital condition in her family. Collateral inferential statistical analyses were implemented in relation to Google Trends database to seek out relevant data in relation to psychedelic substances and their corresponding geographic mapping.
\end{abstract}

Keywords: Novel Psychoactive Substances, NPS, Hallucinogens, Psychotropic drugs, monoamines, addictive behavior, substance-related disorders, mydriasis

\section{Background}

Novel psychoactive substances (NPS), also known as research chemicals or designer drugs, are a group of substances, including chemicals that can either stimulate (stimulants) or inhibit (depressants) the nervous system, particularly the central nervous system (Brew, 2016; Dargan \& Wood, 2013). According to the classification scheme reported by the European Monitoring Centre for Drugs and Drug Addiction (EMCDDA), NPS can be categorised into; cannabis and cannabimimetic, phenethylamines, cathinones, tryptamines, piperazines, pipradrol derivatives, and a seventh miscellaneous group which is composed predominantly of CNS stimulants (Dargan and Wood, 2013; Orsolini et al., 2016). This taxonomy is based on the structural chemistry of 252 substances that were reported to the European Monitoring Centre for Drugs and Drug Addiction (EMCDDA) in between 1997 and 2012. The exponential rise in of the NPS phenomenon is considered to be correlated with the logarithmic growth of the information and communication technologies (Al-Imam et al., 2016; Al-Imam et al., 2017).

The majority of these substances possess addictive properties. Hence, substance users and misusers may develop dependence syndrome, withdrawal manifestations, or adverse reactions (Fazel et al., 2006). These substance act on various neurotransmitters within the nervous system, including the central nervous system (CNS) and the peripheral nervous system (PNS) (Dargan \& Wood, 2013; Vaz et al., 2014). The key neurotransmitters are monoamines including dopamine, serotonin, and catecholamine. In fact, NPS exert their effects via their high selective affinity towards monoamine transporters (MATs); MATs include serotonin transporter (SERT), dopamine transporter (DAT), and norepinephrine (NET) (Gainetdinov and Caron, 2003; Rothman and Baumann, 2003). Generally speaking, MATs are located just around the synaptic cleft (peri-synaptically); they are responsible for the reuptake of monoamines back from the synaptic cleft into the cytoplasm of the presynaptic neurones (Cozzi et al., 2009'; Liechti, 2015). Therefore, the action of NPS on the body systems, both centrally and peripherally, can be attributed to changes achieved via MATs. This manuscript will present a conglomerate study of a case report of an eighteen years old female patient and an (ab)user of NPS and psychedelic substances (hallucinogens) as early as 
the age of eleven years old, at which she started smoking pot and weed (cannabis and marijuana), and several other substances later on. NPS can induce several physiologic changes including ocular alterations (Hohmann et al., 2014). For example, morphometric variations in the dimension (diameter) of the pupillary aperture leading to either pupillary constriction (miosis) or dilation (Mydriasis). In the case of this psychedelic user, she has developed a mydriatic pupil as a consequence of substance abuse. Fortunately, the patient had no complaint with the exception of some photosensitivity and an occasional mild burning sensation affecting both eyes.

\section{Case Report}

The patient is an eighteen years old female of the Caucasian ethnicity from Australasia, specifically New Zealand, she has a light coloured skin of Fitzpatrick type-1 category (Eilers et al., 2013; Majewski et al., 2016). She is a right-handed artist; she has a past history of substance use and misuse starting at the age of eleven years, smoking weed (cannabis and hashish); at that age she developed an abnormally and continuously dilated pupil (Figure 1) leaving a thin rim of blue iridial tissue, the condition is affecting both eyes (bilaterally) though both pupils still react to light, including sunlight. She had no complaints except for the intolerance to sunlight, both direct and indirect, which mandates wearing protective UV sunglasses as advised by a specialist optometrist. Hence, the patient is almost unbothered by her condition; she described it by saying; my eyes always look like this, I have constantly dilated pupils, haha, not even tripping. In fact, she considers her overall eye appearance as sexier than the normal eye. However, she was bothered of the potential eye or retinal damage from overexposure to sunlight.

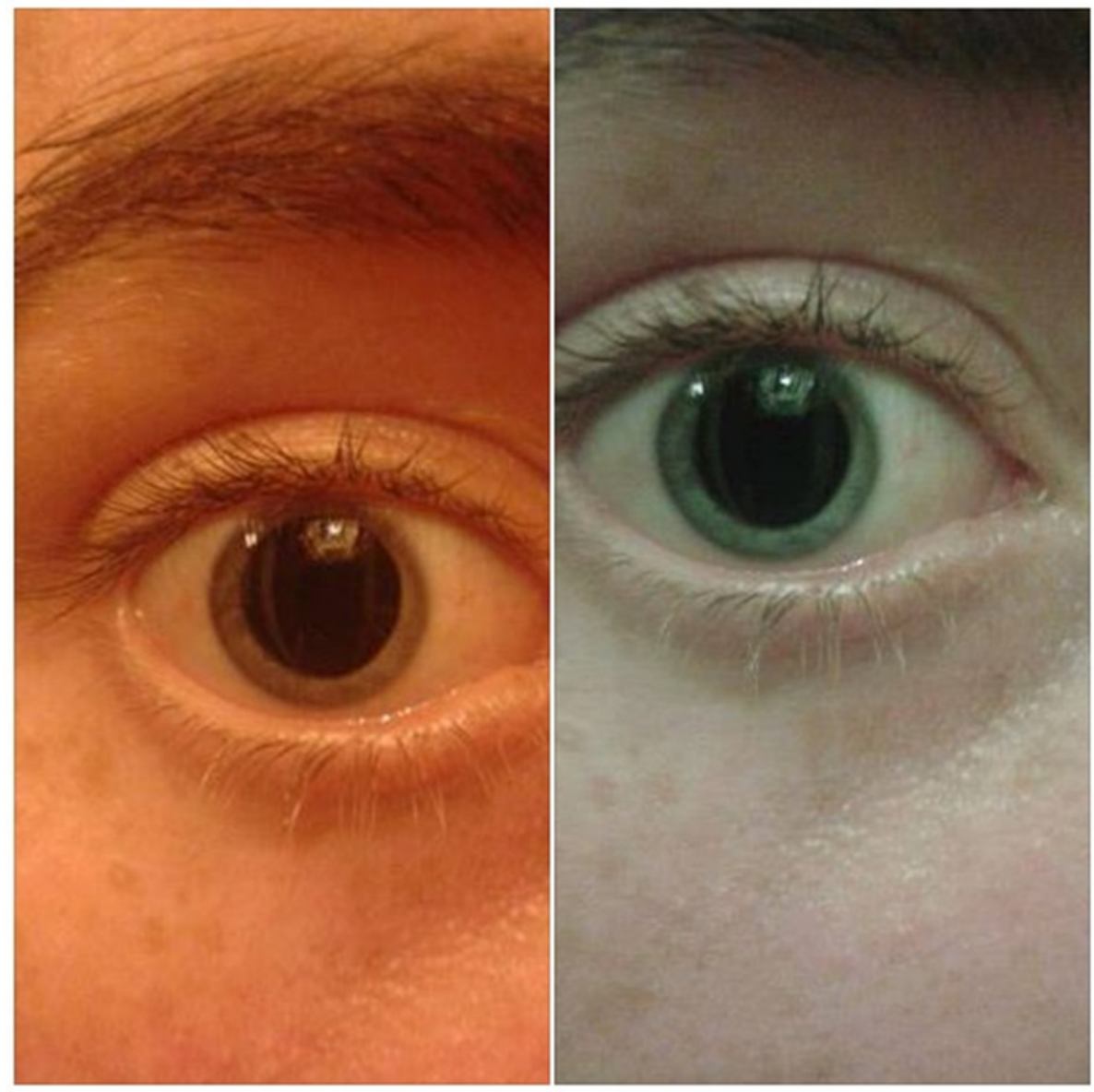

Figure 1. Dilated Right Pupil of a Female Psychedelics' User

* The photograph has been consented by the patient.

The patient has correlated her eye condition with the use of hallucinogens, primarily with LSD (acid) and psilocybin mushrooms. Furthermore, her condition started at the age of eleven years in association with substance use. Hence, the condition cannot be congenital. In 1992, the $1^{\text {st }}$ case of a bilateral congenital Mydriasis was reported in the literature (Richardson and Schulenburg, 1992). The New Zealander patient also had a past medical history, being treated with citalopram and Ritalin for the management of her chronic endogenous depression and 
attention deficit hyperactivity disorder (ADHD); she has been on these medications for several years. She also admitted using tramadol, opium, and opioid derivatives; these substances induce a paradoxical effect on her pupil leading to some degree of pupillary constriction. The patient had no prior history of head trauma, brain tumours, or any other neurological conditions. Furthermore, a thorough neurological and radiological exam were fully healthy; an MRI of the head and neck region was also entirely normal.

Analyses of Google Trends database were done in relation to the most famous psychedelic substances. Google Trends database reflect the attentiveness (interest) of surface web users in connection with any item that can be searched via Google search engine (Carrière - Swallow and Labbé, 2013; Gamma et al., 2016). The analyses are retrospective and reflect an extrapolation of data generated from millions of surface web users. Accordingly, this manuscript is considered as a hybrid study of a retrospective analysis (level-2a) and a case report (level-5). The level-of-evidence is in accordance with the classification system imposed by the Oxford Centre for Evidence-based Medicine (CEBM) (Phillips et al., 2017; Smith and Rennie, 2014). The level-of-evidence of bibliographic materials has also been analysed in accordance with CEBM (Table 1).

Table 1. Critical Analysis of the Cited Literature.

\begin{tabular}{|c|c|c|c|c|c|c|c|}
\hline & & $\begin{array}{l}\text { Web } \\
\text { Pages }\end{array}$ & $\begin{array}{l}\text { Textbooks } \\
\text { and Expert } \\
\text { Opinions }\end{array}$ & $\begin{array}{l}\text { Reviews } \\
\text { and } \\
\text { Systematic } \\
\text { Reviews }\end{array}$ & $\begin{array}{l}\text { Observational } \\
\text { Studies }\end{array}$ & $\begin{array}{l}\text { Experimental and } \\
\text { Quasi-experimental }\end{array}$ & Total \\
\hline \multicolumn{2}{|c|}{ Level-of-Evidence } & 5 & 5 & $2 b$ or $1 \mathrm{a}$ & $2 b$ & $3 b$ to $1 b$ & \\
\hline \multirow{3}{*}{$\begin{array}{l}\text { Statistical } \\
\text { Analysis }\end{array}$} & None & 5 & 2 & 9 & 0 & 0 & 16 \\
\hline & Descriptive & 0 & 3 & 5 & 3 & 2 & 13 \\
\hline & Inferential & 0 & 1 & 3 & 9 & 8 & 21 \\
\hline \multicolumn{2}{|c|}{ Total Number } & 5 & 6 & 17 & 12 & 10 & 50 \\
\hline \multirow{2}{*}{$\begin{array}{l}\text { Publication } \\
\text { Date }\end{array}$} & Before 2012 & 0 & 2 & 6 & 2 & 6 & 16 \\
\hline & After 2012 & 5 & 4 & 11 & 10 & 4 & 34 \\
\hline
\end{tabular}

\section{Discussion}

\subsection{Google Trends: Psychedelics}

Analyses were done based on data retrieved from Google Trends data (Figure 2 to 4 ) for the period from the beginning of 2012 to the end of 2016. The analysis included the most famous psychedelics including; Lysergic acid diethylamide (LSD), MDMA, Psilocybin, Phencyclidine (PCP), Ketamine, N,N-Dimethyltryptamine, Dextromethorphan, Peyote, Ayahuasca, Salvia divinorum, Ergine, NBOMe, AL-LAD, alpha-Methyltryptamine, 2,5-Dimethoxy-4-bromoamphetamine, and TMA-6 (Dargan and Wood, 2013; Psychedelic.com, 2017). The analysis of variance and covariance (ANOVA) test has shown a significant difference $(p$-value $<0.001)$ between all these psychedelics. Statistical testing using Student's t-test was also carried out; LSD was the most popular psychedelic, it was even more popular than MDMA $(p<0.001)$. 
120
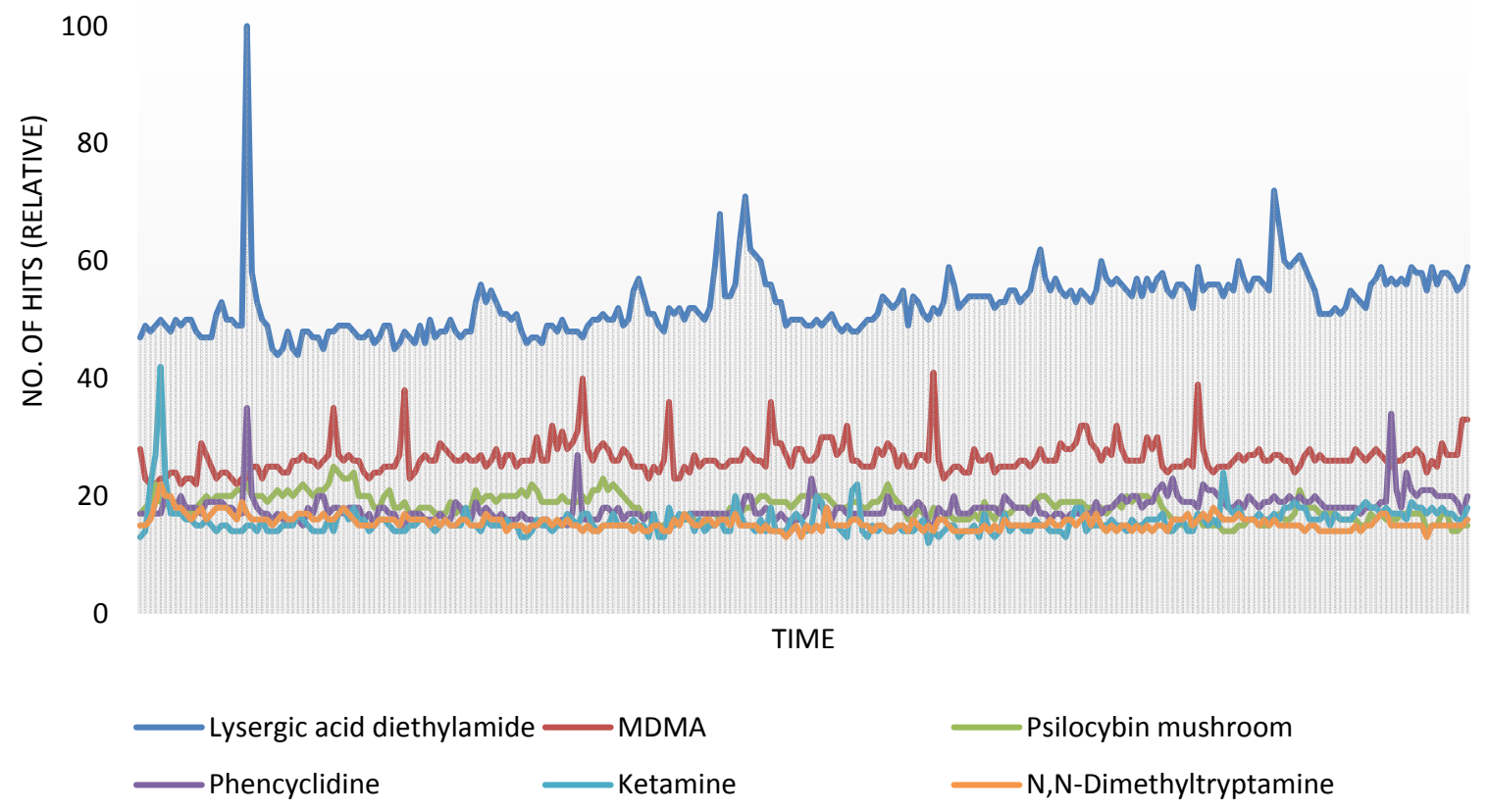

Figure 2. Google Trends of Psychedelics (2012-2016): Lysergic acid diethylamide, MDMA, Psilocybin, Phencyclidine, Ketamine, and N,N-Dimethyltryptamine

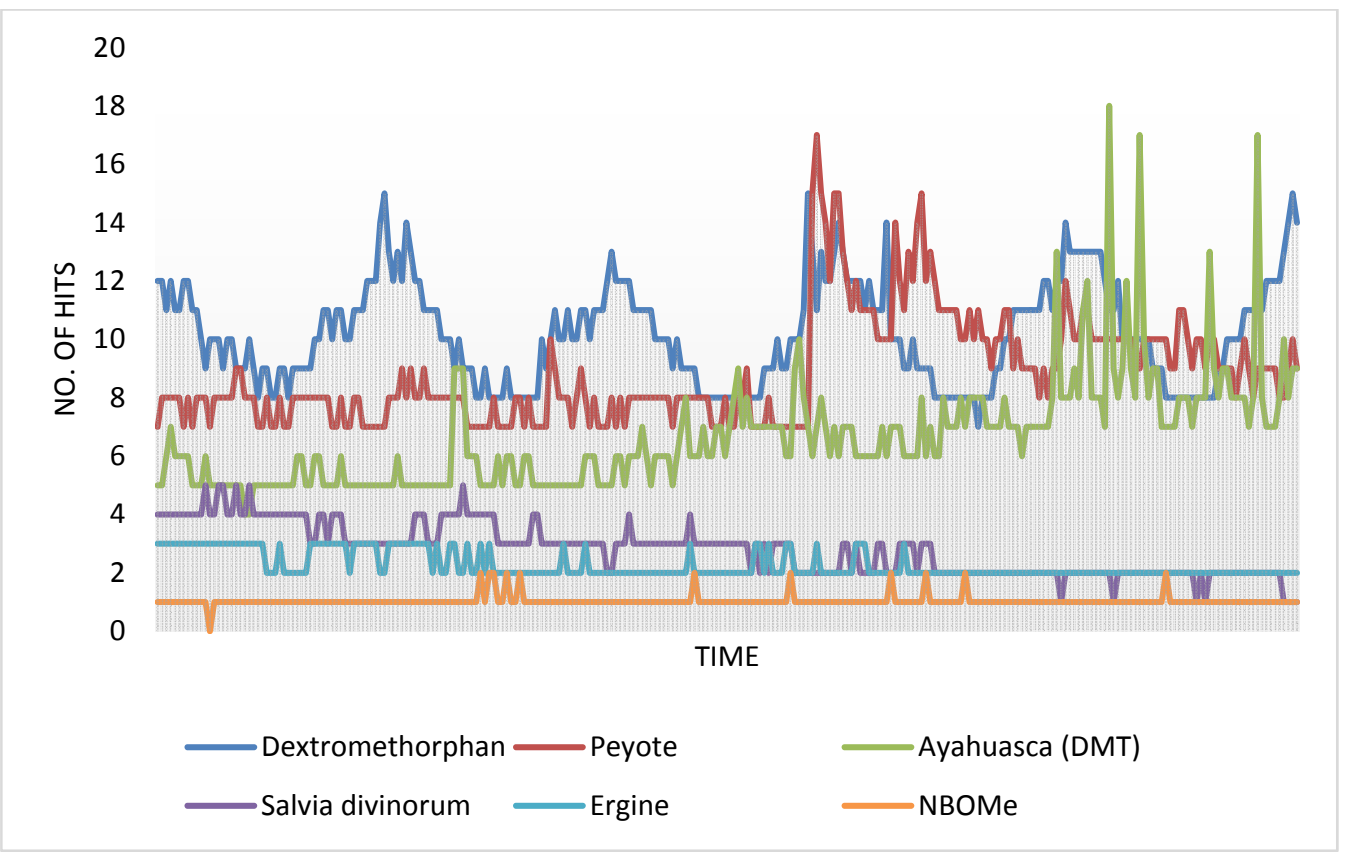

Figure 3. Google Trends of Psychedelics (2012-2016): Dextromethorphan, Peyote, Ayahuasca, Salvia divinorum, Ergine, and NBOMe 


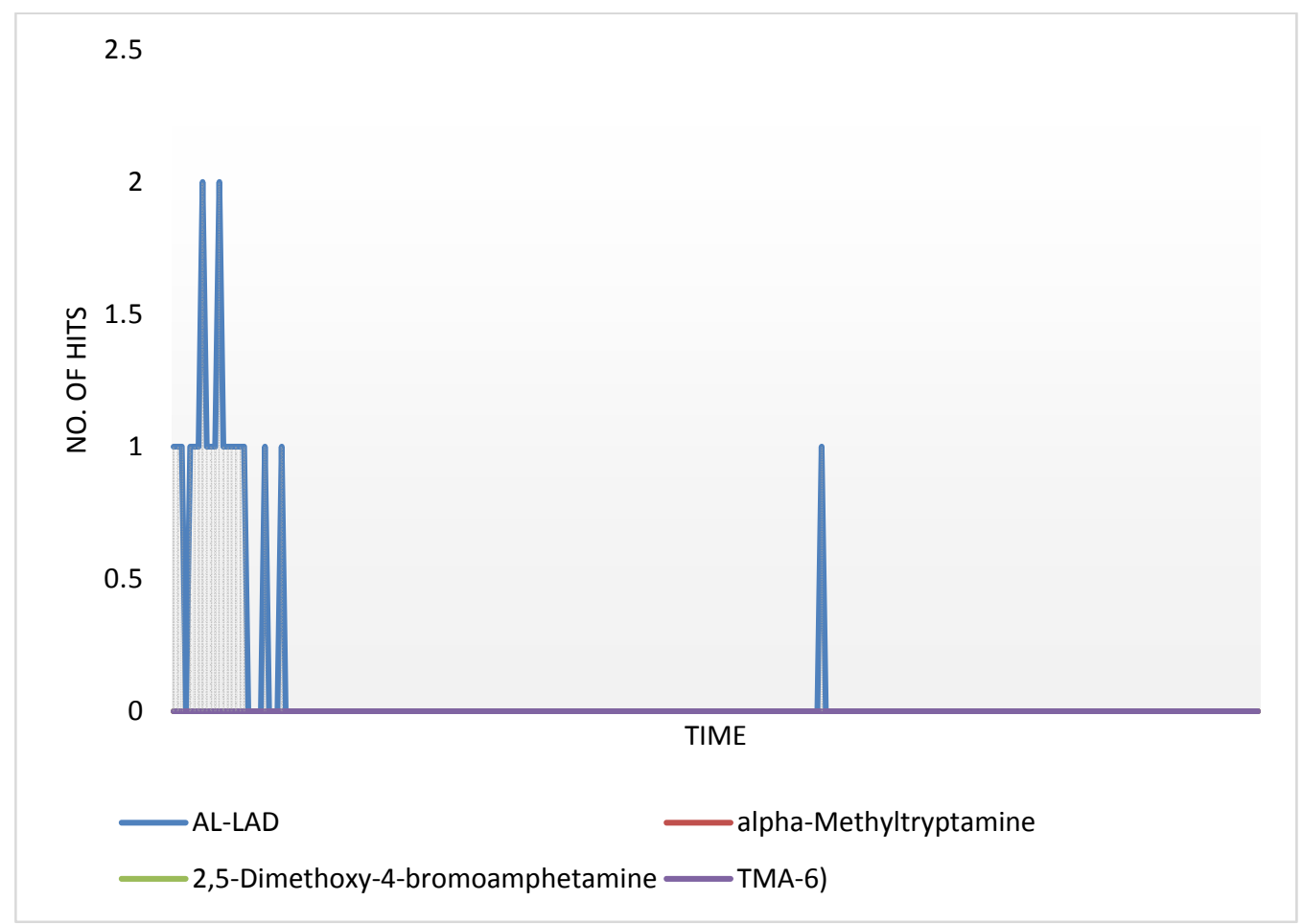

Figure 4. Google Trends of Psychedelics (2012-2016): AL-LAD, alpha-Methyltryptamine, 2,5-Dimethoxy-4-bromoamphetamine, and TMA-6

Furthermore, the trends were highly oscillating, there was no particular pattern, apart from incremental changes (spikes) in the trends during the holidays in the developed countries, specifically during Christmas and the New Year celebrations (Bellis et al., 2007; Halpern and Mechem, 2001; Lai et al., 2013). LSD and MDMA appeared to be the most popular psychedelics on the surface web, while Psilocybin, Phencyclidine, Ketamine, and N,N-Dimethyltryptamine seemed to be of comparable popularity. Geographic mapping (geo-mapping) of the trends (Figure 5) revealed that these substances were highly sought out by surface web users from the developed countries. The top ten countries were; the United States, Estonia, Australia, New Zealand (rank $4^{\text {th }}$ ), Paraguay, Canada, Georgia, Chile, United Kingdom, and Norway. The Middle East accounted for a minute fragment of $3 \%$ of the entire geo-map. The Middle Eastern countries and Arabic countries in which the psychedelics were most popular, included (in descending order); Israel $\left(1^{\text {st }}\right)$, Iran $\left(2^{\text {nd }}\right)$, Morocco, United Arab Emirates, Turkey, Egypt, and the Kingdom of Saudi Arabia. 


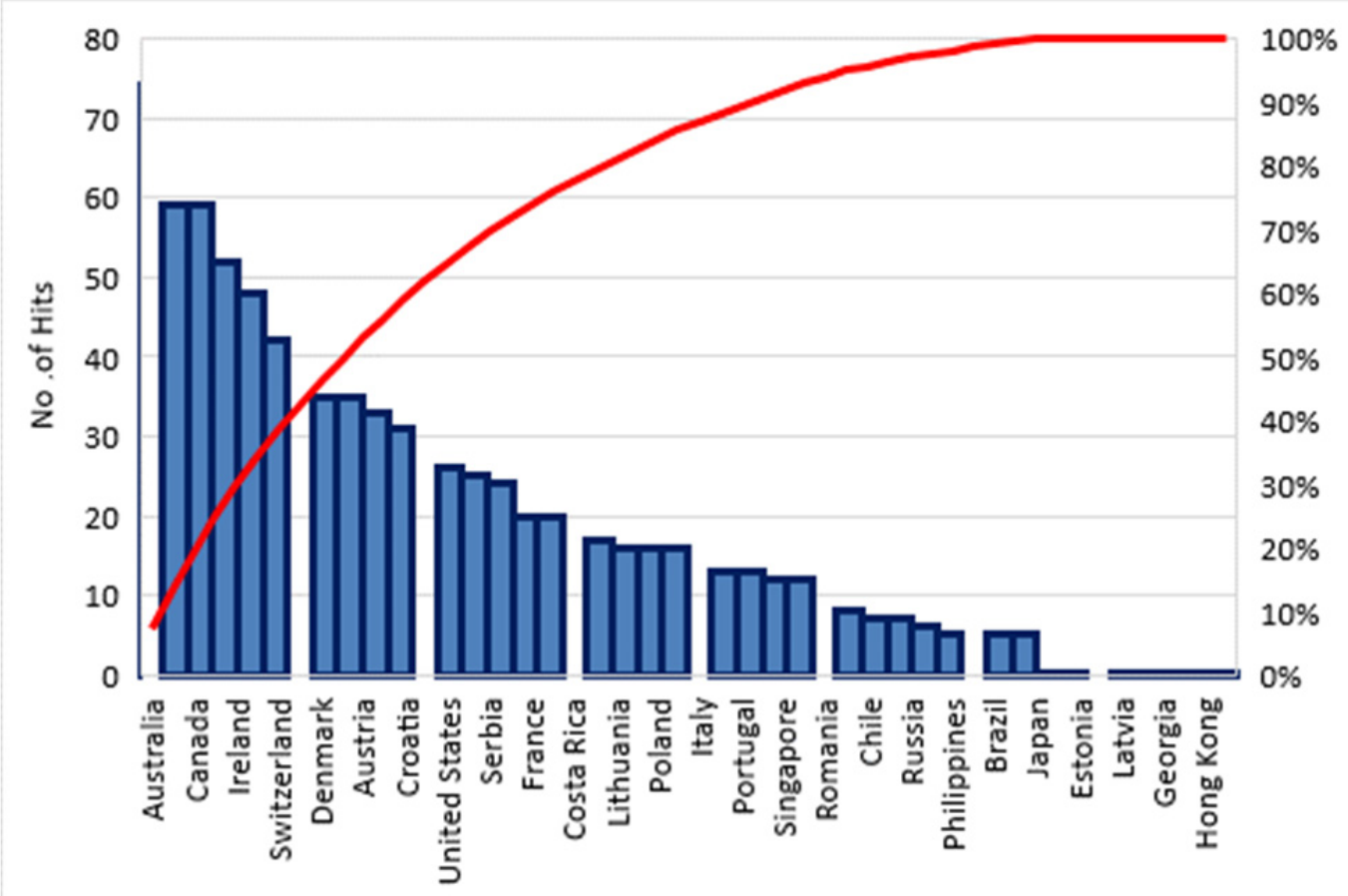

Figure 5. Google Trends: Geo-mapping of the Most Popular Psychedelics

\subsection{Case Discussion}

In Renaissance Italy, Italian ladies used to apply an extract from the berries of Atropa Belladonna as eye drops to both eyes; the purpose was to create artificially dilated pupils, it was considered a sign of beauty. Belladonna is the Italian for a beautiful lady (Abbaspour et al., 2016; Dimitrov et al., 2005). The extract contains anticholinergic substances including atropine, scopolamine, and hyoscyamine. Though it may still be considered as a sign of beauty, it increases the sensitivity towards sunlight (photosensitivity) particularly in fair skin individuals and Caucasians of Fitzpatrick skin type-1 and type-2 (Wilkes et al., 2015). However, in this case, the pupillary changes (mydriasis) were brought by the pathophysiologic effect of possibly more than one substance, primarily hallucinogenic agents via the sympathomimetic and parasympathomimetic-related properties (Śramska et al., 2017).

Changes in the pupillary dimensions are brought up by either an increment or a decrement in its diameter via the action of iridial smooth muscles, both longitudinal (dilator pupillae) and circular (sphincter pupillae) (Vaz. et al., 2014). The autonomic nervous system (ANS), an integral component of the PNS, is responsible for the automatic (visceral) control of the pupillary aperture (Patton, 2015). The sympathetic nervous system (SNS) usually mediate pupillary dilation (mydriasis), while the parasympathetic nervous system, via the oculomotor nerve (cranial nerve III) and its modulatory effect over the ciliary autonomic ganglion, mediates pupillary constriction (miosis) (Patton, 2015; Presland and Price, 2014). Changes in the sympathetic or parasympathetic tone (neuronal activity) are brought up by changes via; reflex mechanism (as in pupillary light reflex), emotional changes affecting the limbic system and the diencephalon specifically the hypothalamus, and the modulation of the neuronal activity in the midbrain specifically pretectal region and the Edinger-Westphal nucleus (accessory oculomotor nucleus). The Edinger-Westphal nucleus houses the presynaptic (preganglionic) parasympathetic motor neurones of the oculomotor nerve which innervate the sphincter pupillae iridial muscles (Daluwatte et al., 2013; Vaz et al., 2014). Hence, this pathway, via the pretectal-accessory oculomotor nucleus, is a critical component of the pupillary light reflex, the afferent and efferent nerves of this pathway are the optic nerve and the oculomotor nerve respectively; the reflex is considered to be a four-neuronal reflex pathway (Kaufman et al., 2011). This reflexive neuronal pathway controls the momentary changes (pupillary unrest under ambient light) of the pupillary aperture with a high accuracy and an ultimate speed (milliseconds) in response to variations in the degree of illumination of the surrounding environment (Ellis, 1983; Heller et al., 1990).

Certain pathophysiological changes can influence the pupillary aperture, these include; the pupillary light reflex mechanism, the tone of SNS or PNS including their autonomic ganglion, pathologies of the midbrain around the 
regions of the cerebral aqueduct of Sylvius including the regions of tectum and tegmentum, hypothalamic region, limbic system, and higher centres. For instance, Horner's syndrome is a condition in which damage affects the function of the upper segments (cervicothoracic) of the paravertebral sympathetic chain, leading to pupillary dilation on the ipsilateral side in addition to ipsilateral eyelid ptosis and hemifacial anhidrosis (Cahill \& Ross, 2015). Several conditions may result in Horner's syndrome, including central (CNS) and peripheral (PNS and ANS), including; syringomyelia, multiple sclerosis, brain tumors, encephalitis, lateral medullary syndrome, cervical rib, thyroid tumors and thyroidectomy, bronchogenic carcinoma, tube thoracostomy, carotid artery dissection, cavernous sinus thrombosis, middle ear infections, sympathectomy, and nerve block procedures (Cahill \& Ross, 2015; Maloney \& Younge, 1980). All these pathological conditions operate either centrally at the level of the hypothalamospinal tract or at the presynaptic sympathetic neurones, or peripherally at the postsynaptic sympathetic neurones. Horner's syndrome can occur either unilaterally or bilaterally; several tests are used to diagnose this syndrome as in the cocaine drop test (Van der Wiel \& Van Gijn, 1986).

Several conditions and agents can cause mydriasis including; injury to the eye and associated neural elements, anticholinergic medications and chemicals such as atropine and scopolamine, the elevated level of oxytocin hormone, and drug use and misuse (Pandit RJ, Taylor, 2000; Richardson \& Schulenburg, 1992). Drugs include cocaine (crack), MDMA (ecstasy), hallucinogenics, methamphetamine (crystal meth), and Toradol (Ketorolac), in addition to several hallucinogenic drugs and entheogen which are not limited to LSD (acid), NBOMe (n-bomb), and Dimethyltryptamine (DMT) (Beharry \& Gibbons, 2016). Stimulants (as in cocaine) and hallucinogens act via increasing the levels of serotonin mainly by working on SERT located centrally (CNS) (Blough et al., 2014). In fact, drugs that may lead to an overall increase in 5-hydroxy tryptamine (serotonin) or a subsequent effect on 5- $\mathrm{HT}_{2 \mathrm{~A}}$ receptor, will exert a mydriatic effect, as in the case of psychedelics (Blough et al., 2014; Liechti, 2015). Other conditions leading to abnormally dilated pupil include; benign episodic unilateral Mydriasis, cranial nerves neuropathy, traumatic brain injury, mydriatic agents used for ophthalmologic examination such as tropicamide (Bersani et al., 2013). Oxytocin, the love hormone, can induce mild to moderate mydriatic effect; oxytocin is related to intimate emotional and social interactions. Hence, it increases in bursts during sexual intercourse; Pitocin (oxytocin) is also medicinally used to induce uterine contraction to either facilitate or induce a normal vaginal delivery (Behnia et al., 2014; Carter, 2014).

Similar cases were reported in drug fora, particularly from abusers of psychedelic substances including both males and females. One of the threads included this comment; My friend has one pupil increased in size and one decreased. Permanently... It happened to him after I made a cacao from weed and we tripped our balls. It looks funny (Erowid.com, 2017; The Terence McKenna Page, 2017). In fact, some psychedelic users reported that they were able to control the size of their pupillary apertures voluntarily, a male has commented; I can change the size of my pupils while looking in the mirror (Erowid.com, 2017; The Terence McKenna Page, 2017). This is remarkable given the fact that iridial muscles are strictly controlled involuntarily by autonomic innervation (The Terence McKenna Page, 2017). Perhaps, some neuronal (or neurochemical) modulation exist in psychedelic (ab)users. Contrary to psychedelic users, users and misusers of opium and opioid substances, experience a constricted (miotic) pupil, or even a pinpoint pupillary aperture (Neice et al., 2017). Heroin, Fentanyl, Codeine, Methadone and Morphine act via stimulation of the PNS (Nuckols et al., 2014). The New Zealander patient presented in this manuscript admitted taking these substances (opioids) too; her pupils could still react with some degree of constriction. She commented saying; I do take tramadol and codeine as well, but they do the opposite to the eyes.

Clinical examination, including a thorough neurological exam, failed to detect any abnormalities apart from the bilaterally dilated pupils. Furthermore, MRI of the regions of the craniocervical and thoracic region of the body could not detect any pathology. It is likely that changes may exist at a cellular level that cannot be detected with the conventional methods; lesions may also exist at the centrally-located nuclei in the midbrain and the hypothalamus. Functional MRI (fMRI) can be useful to detect these changes, but it was not available in the medical institute at which the patient was examined (Mueller et al., 2016; Rubia et al., 2014). Transcranial magnetic stimulation (TMS) might be of value in detecting lesions in the limbic system, temporal lobe, or the prefrontal cortex. However, TMS is not suitable to detect deep-seated lesions neither for the hypothalamus nor for the midbrain (Lopez-Ibor et al., 2008; O'Shea \& Walsh, 2007).

\section{Conclusion}

The data retrieved via statistical analyses of Google Trends database, specifically the geo-mapping, provided insightful data in relation to hallucinogens. Australia and New Zealand were ranked $3^{\text {rd }}$ and $4^{\text {th }}$ respectively as the countries in which surface web users were most interested in psychedelic substances. On the other hand, Acid (LSD) was the most popular hallucinogenic substance worldwide. 
The case of the New Zealander female presented in this manuscript was in line with the retrospective analyses of the trends. The patient had a frequent use of NPS, psychedelics, and other psychoactive chemicals including antidepressant. It can be inferred that the burden of (ab)use of hallucinogenic substances and other NPS chemicals is not to be underrated, particularly in the developed world. These substances can be abused as early as childhood leading to irreversible consequences include adverse pathophysiological changes of body systems, chronic morbidities, dependence syndrome, incidents of intoxications, and even fatalities and sudden death. The magnitude of these dangers is obscure in relation to the developing countries including; the Middle East, Asia, Africa, and Latin America. In connection with the Middle East, Iran and Israel seem to be in the lead with regards to the geo-mapping based on data retrieved from Google Trends database, which necessitates more in-depth epidemiological investigations.

\section{Acknowledgements}

Appreciation and gratitude to the administration of The Terrance McKenna Page, a private group located on the Facebook social communication medium; the group is dedicated for psychedelics users. The author would also like to acknowledge efforts of Dr Mayasa Mohammed Al-Hyali, for her insightful remarks in relation to the background section of this manuscript.

\section{Competing Interests Statement}

The author has no competing interests to be declared.

\section{Source of Funding}

There is no external funding; this study was entirely self-funded.

\section{References}

Abbaspour, A., Khadiv Parsi, P., Khalighi-Sigaroodi, F., \& Ghaffarzadegan, R. (2016). Optimization of Atropine Extraction Process from Atropa Belladonna by Modified Bubble Column Extractor with Ultrasonic Bath. Iranian Journal of Chemistry and Chemical Engineering (IJCCE), 35(4), 49-60.

AL-Imam, A., Santacroce, R., Roman - Urrestarazu, A., Chilcott, R., Bersani, G., Martinotti, G., \& Corazza, O. (2017). Captagon: use and trade in the Middle East. Human Psychopharmacology: Clinical and Experimental, $32(3)$.

Al-Imam, A., Simonato, A. P., \& Corazza, O. (2016). Haloperidol, an old antipsychotic with potential use by NPS users in Iraq. Research and Advances in Psychiatry, 3(3), 81-84. Retrieved from https://www.rapjournal.eu/materiale_cic/948_3_3/8031_haloperidol/article.htm

Beharry, S., \& Gibbons, S. (2016). An overview of emerging and new psychoactive substances in the United Kingdom. Forensic science international, 267, 25-34. https://doi.org/10.1016/j.forsciint.2016.08.013

Behnia, B., Heinrichs, M., Bergmann, W., Jung, S., Germann, J., Schedlowski, M., ... \& Kruger, T. H. (2014). Differential effects of intranasal oxytocin on sexual experiences and partner interactions in couples. Hormones and behavior, 65(3), 308-318. https://doi.org/10.1016/j.yhbeh.2014.01.009

Bellis MA, Hughes KE, Dillon P, Copeland J, Gates P. Effects of backpacking holidays in Australia on alcohol, tobacco and drug use of UK residents. BMC Public Health;7(1), 1. https://doi.org/10.1186/1471-2458-7-1

Bersani, F. S., Corazza, O., Simonato, P., Mylokosta, A., Levari, E., Lovaste, R., \& Schifano, F. (2013). Drops of madness? Recreational misuse of tropicamide collyrium; early warning alerts from Russia and Italy. General Hospital Psychiatry, 35(5), 571-573. https://doi.org/10.1016/j.genhosppsych.2013.04.013

Blough, B. E., Landavazo, A., Decker, A. M., Partilla, J. S., Baumann, M. H., \& Rothman, R. B. (2014). Interaction of psychoactive tryptamines with biogenic amine transporters and serotonin receptor subtypes. Psychopharmacology, 231(21), 4135-4144. https://doi.org/10.1007/s00213-014-3557-7

Brew, I. (2016). Novel psychoactive substances. The British Journal of General Practice, 66(644), 125. https://doi.org/10.3399/bjgp16X684253

Cahill, J. A., \& Ross, J. (2015). Eye on Children: Acute Work-up for Pediatric Horner's Syndrome. Case Presentation and Review of the Literature. The Journal of emergency medicine, 48(1), 58-62. https://doi.org/10.1016/j.jemermed.2014.07.041

Carrière - Swallow, Y., \& Labbé, F. (2013). Nowcasting with Google Trends in an emerging market. Journal of Forecasting, 32(4), 289-298. https://doi.org/10.1002/for.1252

Carter, C. S. (2014). Oxytocin pathways and the evolution of human behavior. Annual review of psychology, 65, 
17-39. https://doi.org/10.1146/annurev-psych-010213-115110

Cozzi, N. V., Gopalakrishnan, A., Anderson, L. L., Feih, J. T., Shulgin, A. T., Daley, P. F., \& Ruoho, A. E. (2009). Dimethyltryptamine and other hallucinogenic tryptamines exhibit substrate behavior at the serotonin uptake transporter and the vesicle monoamine transporter. Journal of neural transmission, 116(12), 1591. https://doi.org/10.1007/s00702-009-0308-8

Daluwatte, C., Miles, J. H., Christ, S. E., Beversdorf, D. Q., Takahashi, T. N., \& Yao, G. (2013). Atypical pupillary light reflex and heart rate variability in children with autism spectrum disorder. Journal of autism and developmental disorders, 43(8), 1910-1925. https://doi.org/10.1007/s10803-012-1741-3

Dargan, P., \& Wood, D. (Eds.). (2013). Novel psychoactive substances: classification, pharmacology and toxicology. Academic Press.

Dimitrov, K., Metcheva, D., \& Boyadzhiev, L. (2005). Integrated processes of extraction and liquid membrane isolation of atropine from Atropa belladonna roots. Separation and purification technology, 46(1), 41-45. https://doi.org/10.1016/j.seppur.2005.04.008

Eilers S, Bach DQ, Gaber R, Blatt H, Guevara Y, Nitsche K, Kundu RV, Robinson JK. Accuracy of self-report in assessing Fitzpatrick skin phototypes I through VI. JAMA dermatology, 149(11), 1289-94. https://doi.org/10.1001/jamadermatol.2013.6101

Ellis, C. J. (1981). The pupillary light reflex in normal subjects. British Journal of Ophthalmology, 65(11), 754-759. https://doi.org/10.1136/bjo.65.11.754

Erowid.com. Erowid Experience Vaults. Retrieved 7 May, 2017, from https://erowid.org/experiences/

Fazel, S., Bains, P., \& Doll, H. (2006). Substance abuse and dependence in prisoners: a systematic review. Addiction, 101(2), 181-191. https://doi.org/10.1111/j.1360-0443.2006.01316.x

Gainetdinov, R. R., \& Caron, M. G. (2003). Monoamine transporters: from genes to behavior. Annual review of pharmacology and toxicology, 43(1), 261-284. https://doi.org/10.1146/annurev.pharmtox.43.050802.112309

Gamma, A., Schleifer, R., Weinmann, W., Buadze, A., \& Liebrenz, M. (2016). Could Google Trends Be Used to Predict Methamphetamine-Related Crime? An Analysis of Search Volume Data in Switzerland, Germany, and Austria. PloS one, 11(11), e0166566. https://doi.org/10.1371/journal.pone.0166566

Halpern, S. D., \& Mechem, C. C. (2001). Declining rate of substance abuse throughout the month. The American journal of medicine, 110(5), 347-351. https://doi.org/10.1016/S0002-9343(00)00749-X

Heller PH, Perry F, Jewett DL, Levine JD. Autonomic components of the human pupillary light reflex. Investigative ophthalmology \& visual science, 31(1), 156-62.

Hohmann, N., Mikus, G., \& Czock, D. (2014). Effects and risks associated with novel psychoactive substances: mislabeling and sale as bath salts, spice, and research chemicals. Deutsches Ärzteblatt International, 111(9), 139.

Kaufman, P. L., Adler, F. H., Levin, L. A., \& Alm, A. (2011). Adler's Physiology of the Eye. Elsevier Health Sciences.

Lai, F. Y., Bruno, R., Hall, W., Gartner, C., Ort, C., Kirkbride, P., ... \& Mueller, J. F. (2013). Profiles of illicit drug use during annual key holiday and control periods in Australia: wastewater analysis in an urban, a semi rural and a vacation area. Addiction, 108(3), 556-565. https://doi.org/10.1111/add.12006

Liechti, M. E. (2015). Novel psychoactive substances (designer drugs): overview and pharmacology of modulators of monoamine signalling. Swiss medical weekly, 145, w14043. https://doi.org/10.4414/smw.2015.14043

Lopez-Ibor, J. J., López-Ibor, M. I., \& Pastrana, J. I. (2008). Transcranial magnetic stimulation. Current Opinion in Psychiatry, 21(6), 640-644. https://doi.org/10.1097/YCO.0b013e3283136a0c

Majewski, S., Carneiro, C., Ibler, E., Boor, P., Tran, G., Martini, M. C., ... \& Nardone, B. (2016). Digital dermoscopy to determine skin melanin index as an objective indicator of skin pigmentation. Journal of Surgical Dermatology, 1(1), 37-42. https://doi.org/10.18282/jsd.v1.i1.15

Maloney, W. F., Younge, B. R., \& Moyer, N. J. (1980). Evaluation of the causes and accuracy of pharmacologic localization in Horner's syndrome. American journal of ophthalmology, 90(3), 394-402. https://doi.org/10.1016/S0002-9394(14)74924-4

Mueller F, Lenz C, Steiner M, Dolder PC, Walter M, Lang UE, Liechti ME, Borgwardt S. Neuroimaging in 
moderate MDMA use: a systematic review. Neuroscience \& Biobehavioral Reviews, 62, 21-34. https://doi.org/10.1016/j.neubiorev.2015.12.010

Neice, A. E., Behrends, M., Bokoch, M. P., Seligman, K. M., Conrad, N. M., \& Larson, M. D. (2017). Prediction of Opioid Analgesic Efficacy by Measurement of Pupillary Unrest. Anesthesia \& Analgesia, 124(3), 915-921. https://doi.org/10.1213/ANE.0000000000001728

Nuckols, T. K., Anderson, L., Popescu, I., Diamant, A. L., Doyle, B., Di Capua, P., \& Chou, R. (2014). Opioid prescribing: a systematic review and critical appraisal of guidelines for chronic pain. Annals of internal medicine, 160(1), 38-47. https://doi.org/10.7326/0003-4819-160-1-201401070-00732

Orsolini, L., Papanti, D., Vecchiotti, R., Valchera, A., Corkery, J., \& Schifano, F. (2016). Novel psychoactive substances. European Psychiatry, 33, S59-S60. https://doi.org/10.1016/j.eurpsy.2016.01.945

O'Shea, J., \& Walsh, V. (2007). Transcranial magnetic stimulation. Current Biology, 17(6), R196-R199. https://doi.org/10.1016/j.cub.2007.01.030

Pandit, R. J., \& Taylor, R. (2000). Mydriasis and glaucoma: exploding the myth. A systematic review. Diabetic medicine, 17(10), 693-699. https://doi.org/10.1046/j.1464-5491.2000.00368.x

Patton, K. T. (2015). Anatomy and Physiology-E-Book. Elsevier Health Sciences.

Phillips, B., Ball, C., Badenoch, D., Straus, S., Haynes, B., \& Dawes, M. (2011). Oxford centre for evidence-based medicine levels of evidence (May 2001). BJU international, 107(5), 870.

Presland, A., \& Price, J. (2017). Ocular anatomy and physiology relevant to anaesthesia. Anaesthesia \& Intensive Care Medicine, 18(1), 27-32. https://doi.org/10.1016/j.mpaic.2016.10.009

Psychedelics.com. The 10 Most Common Psychedelic Drugs. Retrieved 7 March, 2017, from http://psychedelics.com/psychedelic-drugs/the-10-most-common-psychedelic-drugs/

Richardson, P., \& Schulenburg, W. E. (1992). Bilateral congenital mydriasis. The British journal of ophthalmology, 76(10), 632. https://doi.org/10.1136/bjo.76.10.632

Rothman RB, Baumann MH. Monoamine transporters and psychostimulant drugs. European journal of pharmacology, 479(1), 23-40. https://doi.org/10.1016/j.ejphar.2003.08.054

Rubia, K., Alegria, A. A., Cubillo, A. I., Smith, A. B., Brammer, M. J., \& Radua, J. (2014). Effects of stimulants on brain function in attention-deficit/hyperactivity disorder: a systematic review and meta-analysis. Biological Psychiatry, 76(8), 616-628. https://doi.org/10.1016/j.biopsych.2013.10.016

Smith, R., \& Rennie, D. (2014). Evidence-based medicine-an oral history. Jama, 311(4), 365-367. https://doi.org/10.1001/jama.2013.286182

Śramska, P., Maciejka, A., Topolewska, A., Stepnowski, P., \& Haliński, Ł. P. (2017). Isolation of atropine and scopolamine from plant material using liquid-liquid extraction and EXtrelut ${ }^{\circledR}$ columns. Journal of Chromatography B, 1043, 202-208. https://doi.org/10.1016/j.jchromb.2016.09.003

The Terence McKenna Page. The Terence McKenna Experience. Retrieved 7 May, 2017, from https://www.facebook.com/groups/terencemckenna/ (accessed).

Van der Wiel, H. L., \& Van Gijn, J. (1986). The diagnosis of Horner's syndrome: use and limitations of the cocaine test. Journal of the neurological sciences, 73(3), 311-316. https://doi.org/10.1016/0022-510X(86)90155-3

Vaz, M. D., Raj, T. D., \& Anura, K. D. (2014). Guyton \& Hall Textbook of Medical Physiology-E-Book: A South Asian Edition. Elsevier Health Sciences.

Wilkes, M., Wright, C. Y., du Plessis, J. L., \& Reeder, A. (2015). Fitzpatrick skin type, individual typology angle, and melanin index in an African population: steps toward universally applicable skin photosensitivity assessments. JAMA dermatology, 151(8), 902-903. https://doi.org/10.1001/jamadermatol.2015.0351

\section{Copyrights}

Copyright for this article is retained by the author(s), with first publication rights granted to the journal.

This is an open-access article distributed under the terms and conditions of the Creative Commons Attribution license (http://creativecommons.org/licenses/by/4.0/). 